\title{
A DESCONSIDERAÇÃO DA PERSONALIDADE JURÍDICA PARA A RESPONSABILIZAÇÃO PATRIMONIAL DE EX-SÓCIO
}

\author{
Fernanda Borghetti Cantali* \\ Aline Woltz Gueno**
}

\section{RESUMO}

A desconsideração da personalidade jurídica é uma medida, jurisprudencialmente criada, para coibir o uso fraudulento e abusivo da pessoa jurídica por seus sócios, haja vista a existência da autonomia patrimonial aliada à limitação de responsabilidade. A hipótese tradicional de aplicação do instituto é aquela que permite o atingimento do patrimônio pessoal do sócio quando comprovado o cometimento de fraude ou de abuso de direito. Ocorre que, além da forma tradicional, a jurisprudência vem construindo outras hipóteses de aplicação do instituto. Um destes casos especiais é a possibilidade de aplicação da desconsideração da personalidade jurídica para alcançar o patrimônio de ex-sócio. Isso é possível quando o sócio, após a utilização inadequada da pessoa jurídica, caracterizando-se a fraude ou o abuso de direito, se retira da sociedade, deixando-a com seu patrimônio esvaziado com o intuito de frustrar os interesses dos credores da sociedade. Neste caso, aplica-se o instituto da desconsideração da personalidade jurídica permitindo-se o alcance do patrimônio pessoal do ex-sócio, o qual participava da sociedade quando da constituição da obrigação inadimplida pela sociedade.

PALAVRAS-CHAVE: Desconsideração da Personalidade Jurídica; Fraude; Abuso de Direito; Ex-sócio.

\footnotetext{
* Professora da Universidade do Vale do Rio dos Sinos - UNISINOS e do Centro Universitário Metodista do Sul - IPA. Advogada. fernandaborghetti@hotmail.com

** Advogada. aline_gueno@hotmail.com
} 


\begin{abstract}
ABSTRAC
The Disregard Doctrine is a remedy developed by courts with the purpose of restraining the fraudulent and abusive use of the corporate entity by its members or shareholders, taking into account not only proprietary autonomy but also the liability limitation which comes along with such autonomy. The Doctrine is traditionally applied in order to reach personal assets of those company's members or shareholders committing fraud or abuse of right, as duly proven. But, besides this traditional use, courts' precedents have been providing for the application of the Doctrine to some other special cases. One of them is the possibility of disregarding the corporate entity as a means to reach the property of a former member or shareholder. Such may occur when this last, after using the corporate veil in an inappropriate manner, either falling within the definition of fraud or abuse of right, leaves the company taking with him/her a great part of its assets so as to thwart creditors' interests. In this case, the Disregard Doctrine may be applied with the purpose of reaching the personal property of such former member or shareholder, who used to be part of the company's ownership at the time the non-performed obligation was contracted.
\end{abstract}

KEYWORDS: Disregard Doctrine; Fraud; Abuse of Right. Former member/ shareholder.

\title{
1. INTRODUÇÃO
}

A desconsideração da personalidade jurídica é um importante instrumento para a coibição de fraude perpetrada por sócios que, através da constituição da sociedade, além da autonomia patrimonial, gozam de limitação de responsabilidade. A aplicação do instituto se dá quando verificado o abuso da personalidade jurídica que implica em prejuízo dos credores. Esse uso abusivo da personalidade jurídica se verifica através da análise de situações objetivas, tais como as tradicionais hipóteses de confusão patrimonial e desvio de finalidade. Caracterizada a fraude ou o abuso de direito, permite-se o afastamento dos efeitos da personalização da sociedade e o atingimento do patrimônio pessoal dos sócios para satisfação de obrigações da sociedade.

Regra geral, quando da desconsideração da personalidade jurídica são atingidos os sócios ou administradores que se beneficiaram do uso abusivo da pessoa jurídica. Contudo, há situ- 
ações em que estes sócios que se beneficiaram do uso abusivo da personalidade jurídica já não fazem mais parte da sociedade quando a questão vem à tona. Nestes casos, o questionamento que se faz é: pode a desconsideração da personalidade jurídica atingir o patrimônio de ex-sócio?

O objetivo do presente estudo é analisar esta situação em especial, qual seja: a possibilidade de aplicação do instituto da desconsideração da desconsideração da personalidade jurídica para responsabilizar ex-sócio.

Para que se configure o caso de responsabilização patrimonial de ex-sócio, através da utilização do instituto da desconsideração da personalidade jurídica, é necessário que a pessoa jurídica seja inadequadamente utilizada pelo então sócio, para burlar o cumprimento das obrigações por ela assumidas. Além disso, é necessário o preenchimento de requisitos específicos que devem ser comprovados para a sua aplicação, os quais serão descritos. Também importante são as consequências da desconsideração, quando aplicada ao caso concreto, como, por exemplo, a possibilidade ou não de o ex-sócio promover ação de regresso contra a sociedade.

Antes de adentrar ao caso especial de aplicação do instituto, tema principal do presente artigo, serão apresentadas algumas noções fundamentais sobre a desconsideração da personalidade jurídica.

\section{NOÇÕES FUNDAMENTAIS SOBRE A DESCONSIDERA- ÇÃO DA PERSONALIDADE JURÍDICA}

A autonomia patrimonial da pessoa jurídica é, sem dúvida nenhuma, um dos cernes do direito societário, a qual minimiza o risco da atividade empresarial impulsionando o empreendedorismo. A relativização do princípio da autonomia patrimonial deve ser permitida com parcimônia, já que a sua institucionalização, sem uma análise mais apurada, traz ao sistema empresarial a consequência nefasta da insegurança jurídica. A indesejada insegurança jurídica, no mínimo, reduz o número de pessoas que empreendem no país e, consequentemente, implica no desaquecimento da economia. 
Contudo, analisando a história das relações sociais e econômicas, evidenciam-se situações em que a autonomia da patrimonial da pessoa jurídica, aliada ao sistema de limitação de responsabilidade dos sócios, permitiu o uso de estratégias maliciosas com o nítido objetivo de frustrar os interesses dos credores das sociedades. Assim, com a finalidade de preservação do princípio da autonomia patrimonial é que a jurisprudência construiu o instituto da desconsideração da personalidade jurídica, a ser aplicado em situações episódicas de uso abusivo da personalidade jurídica em detrimento dos credores.

Antes da desconsideração da personalidade jurídica, a única forma de coibição do uso abusivo ou fraudulento da sociedade em detrimento dos credores era a dissolução da mesma. Com a desconsideração, a qual é aplicada de forma episódica e casuística, coíbe-se o uso abusivo da personalidade jurídica, preservando-se a sociedade e a pessoa jurídica.

A criação da personalidade jurídica teve um importante papel, haja vista a função social por ela exercida, que além diminuir os riscos do empreendedorismo, auxiliou a fomentar a livre iniciativa, o que gerou a criação de novos postos de trabalho e estimulou a geração e circulação de riquezas, produtos e serviços. ${ }^{1} \mathrm{~A}$ sua principal finalidade é a separação patrimonial que se estabelece entre a pessoa jurídica e as pessoas que a compõem enquanto sócias. Além de garantir a autonomia patrimonial, dependendo do tipo de sociedade, agrega-se ainda a limitação de responsabilidade dos sócios ao capital investido. ${ }^{2}$

A existência legal da pessoa jurídica, conforme dispõem os artigos $985^{3}$ e $1.150^{4}$ do Código Civil, se dá a partir da inscrição

1 GAMA, Guilherme Calmon Nogueira da. Desconsideração da Personalidade Jurídica: visão crítica da jurisprudência. São Paulo: Atlas, 2009, p. 4.

2 REQUIÃO, Rubens. Curso de Direito Comercial. 30. ed. rev. e atual. São Paulo: Saraiva, 2011, p. 456.

3 Art. 985, CC: A sociedade adquire personalidade jurídica com a inscrição, no registro próprio e na forma da lei, dos seus atos constitutivos (arts. 45 e 1.150).

4 Art. 1150, CC: 0 empresário e a sociedade empresária vinculam-se ao Registro Público de Empresas Mercantis a cargo das Juntas Comerciais, e a sociedade 
do seu ato constitutivo ${ }^{5}$, contrato ou estatuto, no registro competente, ou seja, no Registro Público de Empresas Mercantis a cargo da Junta Comercial, no caso de exercício de atividade empresarial (empresas individuais de responsabilidade limitada e sociedades empresarias $^{6}$ ) ou no Registro Civil das Pessoas Jurídicas, no caso de exercício de atividade econômica civil (sociedade simples ${ }^{7}$ ). ${ }^{8}$

A atribuição de personalidade jurídica própria aos entes abstratos gera uma série de consequências ${ }^{9}$. Uma delas é a respon-

simples ao Registro Civil das Pessoas Jurídicas, o qual deverá obedecer às normas fixadas para aquele registro, se a sociedade simples adotar um dos tipos de sociedade empresária.

5 "Nem sempre o registro do contrato de sociedade é indispensável para conferir personalidade jurídica à sociedade, como ocorre na denominada sociedade em conta de participação, cuja atividade constitutiva do objeto social é exercida unicamente pelo sócio ostensivo, em seu nome individual (artigo 991 do Código Civil) e sob sua própria e exclusiva responsabilidade, valendo-se dos aportes dos sócios ocultos." MADALENO, Rolf. A desconsideração judicial da pessoa jurídica e da interposta pessoa física no direito de família e no direito das sucessões. 2.ed. Rio de Janeiro: Forense, 2009, p. 15.

6 Conforme dispõe o Artigo 966 do Código Civil, considera-se empresário todo aquele que exerce profissionalmente atividade econômica organizada para a produção ou a circulação de bens ou de serviços, portanto, podendo ser tanto pessoa física (no caso de empresário individual), quanto pessoa jurídica (no caso de sociedade empresária e de empresa individual de responsabilidade limitada). Já o Artigo 967 do Código Civil, determina que trata-se de obrigação legal a inscrição do empresário no Registro Público de Empresas Mercantis, sendo este um requisito de sua regularidade e não de sua caracterização (Enunciado 199 do CFJ). É importante ressaltar que embora o empresário individual seja cadastrado no CNPJ (Cadastro Nacional de Pessoas Jurídicas), ele não é uma pessoa jurídica, e sim uma pessoa física que exerce atividade empresarial. RAMOS, André Luiz Santa Cruz. Direito Empresarial Esquematizado. 3.ed. rev., atual. e ampl. Rio de Janeiro: Forense; São Paulo: Método, 2013, p. 57-65.

7 Na sociedade simples os profissionais intelectuais exercem atividade econômica coletivamente e, como estes profissionais não são considerados empresários, por força do disposto no Artigo 966, parágrafo único do Código Civil, a sociedade por eles constituída também não é empresária.

8 NEGRÃO, Ricardo. Manual de direito comercial e de empresa: Teoria da empresa e direito societário. 8.ed. São Paulo: Saraiva, 2011, p. 265.

9 Segundo Ricardo Negrão, são efeitos da personalização jurídica: a titularidade negocial e processual, a individualidade própria, a responsabilidade patrimonial, e a alteração em sua estrutura possibilitando a modificação 
sabilidade patrimonial pessoal, a qual decorre da sua autonomia patrimonial. ${ }^{10}$ Ou seja, pelas obrigações da pessoa jurídica responde o patrimônio dela própria, o qual é autônomo em relação aos patrimônios dos sócios. Há sociedades em que a lei autoriza o ingresso no patrimônio pessoal dos sócios para satisfação das obrigações da sociedade, quando o patrimônio desta se esgota. ${ }^{11}$ Contudo, essa é a razão pela qual estas sociedades estão em desuso. Os sócios não irão optar por um tipo de sociedade que coloca em risco seu patrimônio pessoal, quando tem a sua disposição tipos de sociedades que limitam sua responsabilidade.

Para que seja aplicada a desconsideração da personalidade jurídica, um dos pressupostos é a existência de responsabilidade limitada dos sócios em relação à pessoa jurídica ${ }^{12}$. Portanto, a desconsideração da personalidade jurídica só tem sentido quando se está diante de sociedades com sócios de responsabilidade limitada, quais sejam: a sociedade limitada, do gênero simples ou empresarial, e a sociedade anônima ${ }^{13}$, bem como diante de empresas individuais de responsabilidade limitadas, as quais,

de sua ordenação interna. NEGRÃO, Ricardo. Manual de direito comercial e de empresa: Teoria da empresa e direito societário. 8.ed. São Paulo: Saraiva, 2011, p. 264-265.

10 RAMOS, André Luiz Santa Cruz. Direito Empresarial Esquematizado. 3.ed. rev., atual. e ampl. Rio de Janeiro: Forense; São Paulo: Método, 2013, p. 405-406.

${ }^{11}$ É o caso das sociedades em nome coletivo, nas quais todos os sócios respondem ilimitadamente pelas obrigações da sociedade quando esgotado o patrimônio social, bem como de parte dos sócios, os sócios comanditados ou diretores, nas sociedades em comandita simples e por ações, respectivamente, nos termos dos artigos 1039, 1045 e 1091 do Código Civil de 2002.

12 Esta restrição ocorre porque nas demais sociedades todos os sócios ou parte deles já respondem de forma ilimitada (caso das comanditas e nome coletivo), assim sendo torna-se desnecessária a desconsideração porque com o simples esgotamento do patrimônio social já autoriza-se que os credores adentrem ao patrimônio pessoal dos sócios, em função do sistema de responsabilidade que eles assumem quando contratam a sociedade. RAMOS, André Luiz Santa Cruz. Direito Empresarial Esquematizado. 3.ed. rev., atual. e ampl. Rio de Janeiro: Forense; São Paulo: Método, 2013, p. 225.

13 REQUIÃo, Rubens. Curso de Direito Comercial. 30. ed. rev. e atual. São Paulo: Saraiva, 2011, p. 447-448. 
em última análise podem ser compreendidas como sociedades limitadas unipessoais ${ }^{14}$.

A desconsideração retira momentaneamente os efeitos da personalidade jurídica, ou seja, com a aplicação do instituto afastam-se os seus efeitos no caso específico. Portanto, não há que se falar em anulação da pessoa jurídica, a qual persiste. Aliás, é em razão da manutenção da higidez do ato constitutivo da sociedade que o termo "despersonalizar" é entendido como inadequado, não sendo considerado sinônimo de desconsideração da personalidade jurídica. Segundo o que esclarece Marcela Blok, "despersonalizar significa anular a personalidade"15, o que, de fato, não acontece.

0 fato de a desconsideração da personalidade jurídica implicar na ineficácia e não na anulação da personalidade jurídica própria atribuída ao ente abstrato está alinhado ao respeito à função social da empresa. ${ }^{16} 0$ referido princípio, conforme Viviane Perez, possui dois desdobramentos, na medida em que a função social pode funcionar como incentivadora do exercício da empresa ou como condicionadora de tal exercício. A função social condicionando o exercício da empresa é a vertente conhecida, caracterizada pela necessidade de respeito os centros de interesses internos (respeito aos direito dos trabalhadores e dos sócios) e externos à empresa (respeito ao meio ambiente, à livre concor-

14 Conforme defendem: VON ADAMEK, Marcelo Vieira; FRANÇA, Erasmo Valladão Azevedo e Novaes. Empresa Individual de Responsabilidade Limitada (Lei no 12.441/2011): Anotações. In: Revista de Direito Mercantil - RDM. São Paulo: Malheiros, 2011, e COELHO, Fábio Ulhoa. Manual de Direito Comercial. 28.ed. rev. atual. e ampl. São Paulo: Editora Revista dos Tribunais, 2016, p. 161.

15 BLOK, Marcela. Desconsideração da personalidade jurídica; uma visão contemporânea. Revista de Direito Bancário e do Mercado de Capitais. São Paulo: Revista dos Tribunais, Ano 16, vol. 59, jan/mar. 2013, p. 102-103.

16 A função social de determinado direito diz respeito à análise do seu exercício para além das pessoas que dele participam, levando em conta também os interesses maiores da sociedade. (PEREZ, Viviane. Função social da empresa, uma proposta de sistematização do conceito. In: ALVES, Alexandre Fereira de Assunção; GAMA, Guilherme Calmon Nogueira da. (Coords.). Temas de Direito Civil Empresarial. Rio de Janeiro: Renovar, 2008, p. 201). 
rência e aos direitos dos credores). Já, pelo viés incentivador, emerge o princípio da preservação da empresa, o qual define que a manutenção desta atende ao interesse coletivo, pois é geradora de empregos, de tributos, auxilia no abastecimento do mercado de consumo, permite a concorrência saudável, enfim, colabora com o desenvolvimento econômico e social. ${ }^{17}$

A desconsideração da personalidade jurídica, na medida em que coíbe a fraude e o abuso de direito, mas, em contrapartida, preserva o ato constitutivo da sociedade, é instituto alinhado com a vertente que concebe a função social como incentivadora do exercício da atividade empresarial. Irrefutável é tal constatação, já que a desconsideração preserva a empresa.

Avançando no estudo sobre o instituto da desconsideração da personalidade jurídica, há que se ressaltar que a sua aplicação concreta depende da constatação do abuso da personalidade jurídica, através da fraude ou abuso de direito praticados. Ensina Fábio Ulhoa Coelho que a fraude é "o artifício malicioso para prejudicar terceiro", enquanto que o abuso de direito é aquele caracterizado pelo "exercício de direito quando dele decorrer prejuízo a terceiros, sem nenhum benefício ao seu titular". ${ }^{18}$

Originalmente, adotava-se uma concepção subjetivista, ou seja, de que este abuso somente era demonstrado através da intenção de prejudicar os credores. ${ }^{19}$ Ocorre que a prova efetiva da fraude contra os credores, através da constatação do dolo dos sócios em detrimento dos credores da sociedade é prova muito difícil que colocava o instituto no ostracismo. Dessa forma, foi necessário construir outra concepção para a aplicação do instituto,

17 PEREZ, Viviane. Função social da empresa, uma proposta de sistematização do conceito. In: ALVES, Alexandre Fereira de Assunção; GAMA, Guilherme Calmon Nogueira da. (Coords.). Temas de Direito Civil Empresarial. Rio de Janeiro: Renovar, 2008, p. 206.

18 COELHO, Fábio Ulhoa. Desconsideração da personalidade jurídica. São Paulo: Editora Revista dos Tribunais, 1983, p. 57.

19 COELHO, Fábio Ulhoa. Desconsideração da personalidade jurídica. São Paulo: Editora Revista dos Tribunais, 1983, p. $54-55$. 
a qual foi chamada de objetivista, segundo a qual o critério para a aplicação da desconsideração estaria na ocorrência de fatos objetivos, como a confusão patrimonial e o desvio de finalidade. ${ }^{20} \mathrm{Ou}$ seja, fatos objetivos que geram presunção de fraude. Os adeptos desta concepção defendem que é desnecessária a demonstração da intenção dos sócios no cometimento do ato abusivo ou fraudulento, bastando que se comprove algum dos fatos graves que autorizam a sua aplicação. ${ }^{21} \mathrm{~A}$ intenção da atual concepção objetivista é estabelecer critérios mais seguros para a aplicação da desconsideração, tornando desnecessária a demonstração da intenção de usar a pessoa jurídica de forma fraudulenta. ${ }^{22}$

A regra matriz da desconsideração da personalidade jurídica, que consagra a utilização do instituto apenas quando do uso abusivo da personalidade jurídica evidenciado por fatos graves, adotando nitidamente a concepção objetivista ${ }^{23}$, está contida no artigo 50 do Código Civil de 2002:

Art. 50, CCB. Em caso de abuso da personalidade jurídica caracterizado pelo desvio de finalidade, ou pela confusão patrimonial, pode o juiz decidir, a requerimento da parte, ou do Ministério Público quando lhe couber intervir no processo, que os efeitos de certas e determinadas relações de obrigações sejam estendidos aos bens particulares dos administradores ou sócios da pessoa jurídica.

O abuso da personalidade jurídica, por conta do desvio de finalidade, ocorre quando a empresa age em desconformidade

20 Há quem, contudo, sustente que as concepções, subjetivista e objetivista, coexistem no ordenamento jurídico brasileiro, ou seja, uma não é excludente da outra, porque complementares. SILVA, Alexandre Couto. A aplicação da desconsideração da personalidade jurídica no direito brasileiro. 2.ed. Rio de Janeiro: Forense, 2009, p. 87-89.

21 RAMOS, André Luiz Santa Cruz. Direito Empresarial Esquematizado. 6.ed. rev., atual. e ampl. Rio de Janeiro: Forense; São Paulo: Método, 2016, p. 473.

22 SILVA, Alexandre Couto. A aplicação da desconsideração da personalidade jurídica no direito brasileiro. 2.ed. Rio de Janeiro: Forense, 2009, p. 90.

23 RAMOS, André Luiz Santa Cruz. Direito Empresarial Esquematizado. 6.ed. rev., atual. e ampl. Rio de Janeiro: Forense; São Paulo: Método, 2016, p. 479. 
com os princípios ou regras legais, ou ainda contrárias ao ato constitutivo da empresa ${ }^{24}$, enquanto que a confusão patrimonial ocorre quando não é nítida a separação entre o patrimônio da pessoa jurídica e do dos seus sócios. ${ }^{25}$

Constatada situação grave como a de promiscuidade patrimonial entre a pessoa jurídica e seus sócios, não há dúvidas de que a desconsideração é o meio adequado para solucionar questões em os credores são colocados em situações de desvantagem. Contudo, a desconsideração somente deve ser utilizada diante de fatos graves, sob pena de aniquilação do princípio da autonomia patrimonial e o seu principal benefício que é a mitigação do risco do exercício de atividade empresarial.

Contudo, não é possível deixar de ressaltar a existência de corrente doutrinária e jurisprudencial que entende possível a aplicação da desconsideração da personalidade jurídica diante do mero prejuízo do credor por força da insolvência da pessoa jurídica, dispensando-se a demonstração do uso abusivo da personalidade jurídica com a finalidade de fraudar terceiros. Tal corrente sofre dura crítica da doutrina comercialista que entende ser ela o reflexo da crise pela qual passam o princípio da autonomia patrimonial da pessoa jurídica e as regras de limitação de responsabilidade. ${ }^{26}$

Os adeptos desta corrente, buscando justificar sua posição, sustentam que não se trata de desrespeito ao princípio da autonomia patrimonial, mas sim privilégio ao credor não negocial, que é aquele que não negocia o seu crédito com o empresário em

24 MADALENO, Rolf. A desconsideração judicial da pessoa jurídica e da interposta pessoa física no direito de família e no direito das sucessões. 2.ed. Rio de Janeiro: Forense, 2009, p. 101.

25 MADALENO, Rolf. A desconsideração judicial da pessoa jurídica e da interposta pessoa física no direito de família e no direito das sucessões. 2.ed. Rio de Janeiro: Forense, 2009, p. 98.

26 RAMOS, André Luiz Santa Cruz. Direito Empresarial Esquematizado. 6. ed. rev., atual. e ampl. Rio de Janeiro: Forense; São Paulo: Método, 2016, p. 477. 
igualdade de condições, como os trabalhadores e consumidores. ${ }^{27}$ Argumentam que o risco patrimonial do exercício da empresa deve ser suportado pelo empreendedor que o assumiu, bem como pelos credores negociais, tais como fornecedores e bancos. ${ }^{28}$

Não há dúvida alguma que a desconsideração da personalidade jurídica pelo simples prejuízo do credor não negocial é o raciocínio que pauta a jurisprudência trabalhista, a qual utiliza também o argumento do caráter alimentar da verba pleiteada, servindo como forma de protecionismo ao trabalhador, considerado hipossuficiente na relação empregatícia. ${ }^{29}$

Tal raciocínio também é aplicado, muitas vezes, no âmbito das relações de consumo. Aliás, o Código de Defesa do Consumidor foi o primeiro a disciplinar a desconsideração da personalidade jurídica no ordenamento brasileiro, no artigo 28. Além de impropriedades trazidas pelo caput do dispositivo, que aplica desconsideração para casos de ato ilícito e violação da lei ou do estatuto ou contrato social, situações que ensejam responsabilidade direta daqueles que praticam tais atos, dispensando por completo a desconsideração ${ }^{30}$, o $5^{\circ}$, a partir de uma leitura equivocadamente independente do caput, autorizaria a aplicação

27 Os credores da pessoa jurídica podem ser os negociais, que são aqueles que têm condições de acrescer ao preço do produto fornecido uma taxa de risco em função de possível perda por conta do princípio da autonomia patrimonial, enquanto que os não negociais são aqueles que não dispõem dos meios acima descritos para se resguardarem, como é o caso dos consumidores e dos empregados. COELHO, Fábio Ulhoa. Curso de direito comercial. 10. ed. rev. e atual. São Paulo: Saraiva, 2013, v.1, p. 81.

28 RAMOS, André Luiz Santa Cruz. Direito Empresarial Esquematizado. 6.ed. rev., atual. e ampl. Rio de Janeiro: Forense; São Paulo: Método, 2016, p. 478.

29 SILVA, Alexandre Couto. A aplicação da desconsideração da personalidade jurídica no direito brasileiro. 2.ed. Rio de Janeiro: Forense, 2009, p. 182.

30 Nesse sentido o Enunciado 229 do CJF: "A responsabilidade ilimitada dos sócios pelas deliberações infringentes da lei ou do contrato torna desnecessária a desconsideração da personalidade jurídica, por não consistir a autonomia patrimonial da pessoa jurídica escudo para a responsabilização pessoal e direta". 
do instituto em análise para os casos de mero prejuízo do credor consumidor. ${ }^{31}$ Veja-se a redação do dispositivo legal:

Art. 28, CDC. 0 juiz poderá desconsiderar a personalidade jurídica da sociedade quando, em detrimento do consumidor, houver abuso de direito, excesso de poder, infração da lei, fato ou ato ilícito ou violação dos estatutos ou contrato social. A desconsideração também será efetivada quando houver falência, estado de insolvência, encerramento ou inatividade da pessoa jurídica provocados por má administração.

(...)

$\S 5$ Tombém poderá ser desconsiderada a pessoa jurídica sempre que sua personalidade for, de alguma forma, obstáculo ao ressarcimento de prejuízos causados aos consumidores.

Além do Código de Defesa do Consumidor, a Lei Antitruste (Art. $34^{32}$ ) e a Lei de Crimes Ambientais (Art. 4ํㅜㄱ), também adotaram os critérios mais flexíveis para a aplicação da desconsideração da personalidade jurídica, tendo em vista a gravidade e o impacto social provocado pelos crimes ambientais ou à ordem econômica.

Cumpre também ressaltar que Fábio Ulhoa Coelho cunhou a nomenclatura teoria maior e teoria menor para fins de identificação das correntes relativas à desconsideração da personalidade jurídica. A teoria maior seria aquela que exige o uso abusivo da personalidade jurídica para a aplicação do instituto, seja calcado na antiga concepção subjetivista, seja na hodierna concepção objetivista. Já a teoria menor representaria o entendimento de que o simples prejuízo do credor não negocial diante da insolvência da

31 RAMOS, André Luiz Santa Cruz. Direito Empresarial Esquematizado. 6.ed. rev., atual. e ampl. Rio de Janeiro: Forense; São Paulo: Método, 2016, p. 477-8.

32 Art. 34: A personalidade jurídica do responsável por infração da ordem econômica poderá ser desconsiderada quando houver da parte deste abuso de direito, excesso de poder, infração da lei, fato ou ato ilícito ou violação dos estatutos ou contrato social. Parágrafo único. A desconsideração também será efetivada quando houver falência, estado de insolvência, encerramento ou inatividade da pessoa jurídica provocados por má administração.

33 Art. 4o: Poderá ser desconsiderada a pessoa jurídica sempre que sua personalidade for obstáculo ao ressarcimento de prejuízos causados à qualidade do meio ambiente. 
pessoa jurídica é suficiente para abrir caminho para a desconsideração da personalidade jurídica, além de ser utilizada apenas em casos legais específicos como as relações de consumo e os crimes ambientais. A nomenclatura teoria maior e menor, embora hoje não mais utilizada pelo seu próprio criador, nas últimas edições de suas obras ${ }^{34}$, ainda é amplamente utilizada pela doutrina e pela jurisprudência, inclusive do Superior Tribunal de Justiça.

A Ministra Nancy Andrighi, em voto paradigmático sobre o tema, aplicando a teoria menor para o ressarcimento dos consumidores no caso da explosão do Shopping Osasco, explicita a distinção entre as teorias da desconsideração:

A teoria menor da desconsideração, por sua vez, parte de premissas distintas da teoria maior: para a incidência da desconsideração com base na teoria menor, basta a prova de insolvência da pessoa jurídica para o pagamento de suas obrigações, independentemente da existência de desvio de finalidade ou de confusão patrimonial. Para esta teoria, o risco empresarial normal às atividades econômicas não pode ser suportado pelo terceiro que contratou com a pessoa jurídica, mas pelos sócios e/ou administradores desta, ainda que estes demonstrem conduta administrativa proba, isto é, mesmo que não exista qualquer prova capaz de identificar conduta culposa ou dolosa por parte dos sócios e/ou administradores da pessoa jurídica. ${ }^{35}$

Não obstante a convicção de que o alargamento do uso da desconsideração da personalidade jurídica é temerária pelas razões já expostas, é importante destacar que ambas as posições, refletidas ou não através da nomenclatura teoria maior e menor, coexistem no mundo jurídico brasileiro, sendo aplicáveis em diferentes casos. ${ }^{36} \mathrm{~A}$ teoria maior é a regra geral, enquanto que

34 COELHO, Fábio Ulhoa. Manual de Direito Comercial. 28.ed. rev. atual. e ampl. São Paulo: Editora Revista dos Tribunais, 2016, p. 124/126.

35 STJ, 3 3 a Turma. REsp.n. 279.273/SP. Relator: Ministro Ary Pargendler, julgado em 04.12.2003.

36 Com o as regras da desconsideração da personalidade jurídica nos casos das relações de consumo, crimes ambientais e infrações à ordem econômica (já havia dispositivo neste sentido na Lei no 8.884/1994, Art. 18) são anterio- 
a teoria menor aplica-se nos casos em que há relação de hipossuficiência (consumidor e trabalhador) ou em função impacto social da conduta cometida (matéria ambiental ou de violação à ordem econômica).

Ainda, importante mencionar que para aplicação da desconsideração da personalidade jurídica nos casos de uso abusivo da personalidade não se exige a demonstração da insolvência da pessoa jurídica. ${ }^{37} \mathrm{O}$ sócio atingido pelos efeitos da desconsideração não poderá utilizar em sua defesa o benefício de ordem ou a subsidiariedade de sua eventual responsabilidade (Artigo 1024 do Código Civil), na medida em que não faria sentido, àquele que se utilizou indevidamente da pessoa jurídica, requerer que primeiramente fossem executados os bens desta, para só então o seu patrimônio estar submetido. Isso seria uma premiação àquele que fez o mau uso da pessoa jurídica. ${ }^{38}$ Portanto, a desconsideração no caso do uso abusivo da personalidade jurídica pode ser entendida como uma forma de punição.

Em derradeira ressalva, reafirma-se que a aplicação da desconsideração da personalidade jurídica deve ocorrer de forma excepcional, apenas nos casos em que a personalidade jurídica serviu de instrumento para o cometimento de abuso contra os credores. Ainda, a desconsideração somente deve ser aplicada

res à regra matriz do artigo 50 do Código Civil de 2002, imaginou-se que o novo tratamento legislativo trazido pela lei geral, calcado no uso abusivo da personalidade jurídica como fundamento para aplicação da desconsideração poderia vir a refrear o uso do instituto alargado consagrado nas regras especiais. Contudo, não foi o que aconteceu, o que se reflete no Enunciado 51 do CJF: "A teoria da desconsideração da personalidade jurídica - disregard doctrine - fica positivada no novo Código Civil, mantidos os parâmetros existentes nos microssistemas legais na construção jurídica sobre o tema”.

37 Nesse sentido o Enunciado 281 do CJF esclarece que para "a aplicação da teoria da desconsideração, descrita no art. 50 do Código Civil, prescinde da demonstração de insolvência da pessoa jurídica", ou seja, pode ser aplicada como uma sanção.

38 SOUZA, André Pagani de. Desconsideração da personalidade jurídica: aspectos processuais. 2.ed. São Paulo: Saraiva, 2011, p. 91. 
quando preenchidos todos os requisitos legais, sob pena de ferimento dos direitos do sócio que terá seu patrimônio atingido para satisfação de obrigações que, em regra, são da sociedade.

Feitas estas observações breves sobre o instituto da desconsideração da personalidade jurídica, do ponto de vista do direito material $^{39}$, cabe analisar o caso especial de sua utilização para atingimento do patrimônio de ex-sócio.

\section{A POSSIBILIDADE DE DESCONSIDERAÇÃO DA PERSONALIDADE JURÍDICA PARA A RESPONSABILIZAÇÃO PATRIMONIAL DE EX-SÓCIO}

Muitas vezes, os sócios que utilizam inadequadamente a pessoa jurídica para o cometimento de fraudes ou atos abusivos, após a prática do ato específico com intuito de frustrar os interesses dos credores, se retiram da sociedade. Tal circunstância mostrou a necessidade de extensão da aplicação da Disregard Doctrine, para que os seus efeitos possam atingir também ex-sócio, a fim de proporcionar maior efetividade aos direitos daqueles credores que foram afetados pelo uso abusivo da personalidade jurídica. ${ }^{40}$

39 O presente estudo restringe-se a análise da desconsideração da personalidade jurídica do ponto de vista do direito material, muito embora atualmente os aspectos processuais estejam sendo debatidos de forma mais presente considerando a novidade trazida pelo Novo Código de Processo Civil: o incidente de desconsideração da personalidade jurídica. Apesar de a desconsideração da personalidade jurídica estar presente nos debates jurídicos há muito tempo e ser amplamente aplicada pelos Tribunais, não havia até então regulamentação do procedimento a ser utilizado para a sua aplicação. Aliás, a lacuna procedimental era apontada como um problema, já que gerava demasiada insegurança jurídica. Dessa forma, o presente capítulo que consagra o incidente de desconsideração da personalidade jurídica é muito bem-vindo e foi apontado pela doutrina processualista como um ponto positivo do novo Código. Sobre o tema sugere-se a leitura de MARINONI, Luiz Guilherme; MITIDIERO, Daniel. O projeto do CPC: críticas e propostas. São Paulo: RT, 2010, p. 80, bem como de CANTALI, Fernanda Borghetti; GUENO, Aline Wolz. Anotações aos artigo 133 a 137. In: MELLO, Rafael Corte; GIORGI JÚNIOR, Rômulo Ponticelli. (Orgs.) Novo Código de Processo Civil Anotado. Charleston, EUA: CreateSpace Independent Publishing Platform, 2015.

40 FORNACIARI JÚNIOR, Clito. Execução: Responsabilidade do Ex-sócio. Revista Magister de Direito Empresarial, Concorrencial e do Consumidor. Porto Alegre: Magister, Fev/Mar, 2005, p. 11. 
Em outras palavras, nos casos em que comprovadamente houve a utilização da pessoa jurídica de forma fraudulenta e, após isso, o sócio se retirou da sociedade, através de uma interpretação extensiva da norma do artigo 50 do Código Civil, poderá ser desconsiderada a personalidade jurídica ignorando-se as alterações contratuais, atingindo, assim, além dos sócios atuais, aqueles que participaram da constituição da obrigação, e já não mais integram a sociedade. ${ }^{41}$

Para o estudo da desconsideração da personalidade jurídica com intuito de alcançar patrimônio de ex-sócio é relevante partir da compreensão da possibilidade de o sócio transferir as suas quotas sociais ou ações, ou ainda de, através do exercício do direito de retirada, deixar de integrar determinada sociedade. ${ }^{42}$

Nas sociedades limitadas, a cessão das quotas sociais é possível desde que observada a forma estabelecida no contrato social, ou, caso este seja omisso, a regra do artigo 1057 do Código Civil:

Art. 1057. Na omissão do contrato, o sócio pode ceder sua quota, total ou parcialmente, a quem seja sócio, independentemente de audiência dos outros, ou a estranho, se não houver oposição de titulares de mais de um quarto do capital social.

0 referido artigo estabelece que, quando a cessão das quotas sociais se der em favor de outro sócio, independe da anuência dos demais sócios, já, quando a cessão se der à terceiro, não poderá haver oposição de sócios que representem mais de vinte

41 FORNACIARI JÚNIOR, Clito. Execução: Responsabilidade do Ex-sócio. Revista Magister de Direito Empresarial, Concorrencial e do Consumidor. Porto Alegre: Magister, Fev/Mar, 2005, p. 11.

42 Além da transferência das quotas sociais e direito de retirada, há ainda mais uma possibilidade do sócio deixar a sociedade, qual seja, através da exclusão, nas hipóteses estabelecidas em lei que são: no caso de mora na integralização das quotas por ele subscritas (Artigo 1004, parágrafo único, do Código Civil) ou por justa causa, caracterizada pela violação ou descumprimento das obrigações sociais, através de ação judicial de iniciativa da maioria dos demais sócios (Artigo 1030 do Código Civil). (COELHO, Fábio Ulhoa. Manual de Direito Comercial. 23. ed. São Paulo: Saraiva, 2011, p. 171) 
e cinco por cento do capital social da sociedade. ${ }^{43}$ Ainda, para que os efeitos da cessão das quotas sociais se operem perante a sociedade e terceiros, é necessário que a alteração contratual pertinente seja averbada no órgão registral competente. ${ }^{44}$

Nas sociedades por ações abertas ${ }^{45}$, a qual tem feição eminentemente capitalista ${ }^{46}$, os títulos representativos da participação societária (ações) são livremente negociáveis, ou seja, nesse tipo de sociedade a entrada de terceiros no quadro social independe da anuência dos demais sócios. ${ }^{47}$ Já, em se tratando de sociedade por ações fechadas, podem existir restrições ao ingresso de novo acionista ${ }^{48}$, desde que estabelecidas no estatuto social. ${ }^{49}$ Assim a disposição do artigo 36 da Lei no 6.404/76:

43 NEGRÃO, Ricardo. Manual de direito comercial e de empresa: teoria da empresa e direito societário. 8 ed. São Paulo: Saraiva, 2011, p. 401.

44 Artigo 1057. Parágrafo único. A cessão terá eficácia quanto a sociedade e terceiros, inclusive para os fins do parágrafo único do art. 1003, a partir da averbação do respectivo instrumento subscrito pelos sócios anuentes.

45 “...a S/A será aberta quando tiver autorização para negociar seus valores mobiliários no mercado de capitais, e fechada quando não tiver autorização para tanto." (RAMOS, André Luiz Santa Cruz. Direito Empresarial Esquematizado. 3. ed. rev., atual. e ampl. Rio de Janeiro: Forense; São Paulo: Método, 2013, p.286)

46 As sociedades em relação a sua composição podem ser classificadas em sociedades de pessoas ou sociedades de capital. Na sociedade de pessoas a figura do sócio tem maior relevância, por existir a chamada affectio societatis, ou seja, um vínculo pessoal que une os sócios, no qual esta baseado o sucesso do empreendimento. Já na sociedade de capital, a figura pessoal do sócio não tem grande relevância, importando apenas a contribuição do sócio ao capital social. (RAMOS, André Luiz Santa Cruz. Direito Empresarial Esquematizado. 3. ed. rev., atual. e ampl. Rio de Janeiro: Forense; São Paulo: Método, 2013, p. 226).

47 CoElHo, Fábio Ulhoa. Manual de Direito Comercial. 23. ed. São Paulo: Saraiva, 2011, p. 211-212.

48 "A sociedade anônima aberta não comporta restrições à circulação das ações". (REQUIÃo, Rubens. Curso de Direito Comercial, 2005, p. 442).

49 REQUIÃO, Rubens. Curso de Direito Comercial. 30. ed. rev. e atual. São Paulo: Saraiva, 2011. V.1., p. 442. 
Art. 36. 0 estatuto da companhia fechada pode impor limitações à circulação das ações nominativas, contanto que regule minuciosamente tais limitações e não impeça a negociação, nem sujeite o acionista ao arbítrio dos órgãos de administração da companhia ou da maioria dos acionistas. Parágrafo único. A limitação à circulação criada por alteração estatutária somente se aplicará às ações cujos titulares com ela expressamente concordarem, mediante pedido de averbação no livro de "Registro de Ações Nominativas".

Para além da cessão de quotas ou de ações, pode também o sócio sair da sociedade exercendo o direito de retirada, o qual pode ser motivado ou imotivado, conforme as hipóteses legais pertinentes. Ricardo Negrão, analisando as sociedades contratuais, explica que o direito de retirada abrange duas modalidades:

(a) o comum, ordinário ou imotivado, que pode ser exercido na sociedade constituída por prazo indeterminado, mediante simples notificação do sócio retirante dirigida aos demais sócios com antecedência mínima de sessenta dias (art. 1.029); e (b) o extraordinário, na hipótese de o contrato ter previsto prazo determinado para a duração da sociedade. Nesse caso, a retirada dependerá do consentimento unânime dos sócios; não sendo concedido, sujeitará o sócio a decisão judicial, em ação de resolução de contrato de sociedade, na qual se buscará demonstrar a justa causa alegada. ${ }^{50}$

No que toca especificamente às sociedades limitadas, o direito de retirada motivado está calcado na disposição do artigo 1077 do Código Civil ${ }^{51}$, através do qual, quando houver modificações

50 NEGRÃO, Ricardo. Manual de direito comercial e de empresa: teoria da empresa e direito societário. 8 ed. São Paulo: Saraiva, 2011, p. 401.

51 Art. 1.077. Quando houver modificação do contrato, fusão da sociedade, incorporação de outra, ou dela por outra, terá o sócio que dissentiu o direito de retirar-se da sociedade, nos trinta dias subsequentes à reunião, aplicandose, no silêncio do contrato social antes vigente, o disposto no art. 1.031. 
contratuais, transformações ${ }^{52}$, fusões ${ }^{53}$, incorporações ${ }^{54}$, poderá o sócio que dissentiu retirar-se da sociedade, no prazo dos 30 dias subsequentes a data da reunião na qual foi tomada a referida decisão. ${ }^{55}$ Já a retirada imotivada está simplesmente calcada na ideia de que se há liberdade de associação, deve também haver liberdade de desassociação, sob pena de que as sociedades adquiram características de perpetuidade ${ }^{56}$.

Na sociedade anônima não existe hipótese de direito de retirada imotivada pelo acionista. Tal direito apenas é concedido motivadamente e nas hipóteses previstas em lei ${ }^{57}$. Mas nas companhias a regra é a livre circulação da participação societária.

No caso do sócio retirar-se da sociedade, este possui o direito à apuração de seus haveres que, conforme conceitua

52 Segundo o Artigo 220, da Lei 6404/76, "a transformação é a operação pela qual a sociedade passa, independentemente de dissolução e liquidação, de um tipo para outro".

53 Conforme estabelece o Artigo 228, da Lei 6404/76, "a fusão é a operação pela qual se unem duas ou mais sociedades para formar sociedade nova, que lhes sucederá em todos direitos e obrigações".

54 De acordo com o Artigo 227, da Lei 6404/76, "a incorporação é a operação pela qual uma ou mais sociedades são absorvidas por outra, que lhes sucede em todos os direitos e obrigações".

55 NEGRÃO, Ricardo. Manual de direito comercial e de empresa: teoria da empresa e direito societário. 8 ed. São Paulo: Saraiva, 2011, p. 415.

56 VON ADAMEK, Marcelo Vieira; FRANÇA, Erasmo Valladão Azevedo e Novaes. Notas sobre a sociedade perpétua. Artigo gentilmente cedido pelos autores.

57 Principais hipóteses de direito de retirada de acionista, conforme a Lei 6404/76, são: Art. 137. A aprovação das matérias previstas nos incisos I a VI e IX do art. 136 dá ao acionista dissidente o direito de retirar-se da companhia, mediante reembolso do valor das suas ações (art. 45), observadas as seguintes normas: I - nos casos dos incisos I e II do art. 136, somente terá direito de retirada o titular de ações de espécie ou classe prejudicadas. Art. 136. I - criação de ações preferenciais ou aumento de classe de ações preferenciais existentes, sem guardar proporção com as demais classes de ações preferenciais, salvo se já previstos ou autorizados pelo estatuto; II alteração nas preferências, vantagens e condições de resgate ou amortização de uma ou mais classes de ações preferenciais, ou criação de nova classe mais favorecida; III - redução do dividendo obrigatório; IV - fusão da companhia, ou sua incorporação em outra; V - participação em grupo de sociedades; VI - mudança do objeto da companhia; IX - cisão da companhia. 
Ricardo Negrão é "o direito do sócio, por ato unilateral seu, de retirar-se da sociedade, levando os fundos que somente lhe caberiam em caso de liquidação"58, a qual se dá nos termos do artigo 1031 do Código Civil ${ }^{59}$.

O sócio que sai da sociedade, seja por cessão de quotas, seja por exercício do direito de retirada, também chamado de direito de recesso, possui responsabilidade residual pelas obrigações sociais contraídas antes da sua saída. Tal responsabilidade se entende pelo prazo de dois anos, a contar da data da averbação ou modificação do contrato, conforme dispõe o parágrafo único do artigo 1003 do Código Civil ${ }^{60}$ e artigo 1032 do Código Civil ${ }^{61}$, e, nos casos de cessão de quotas, há solidariedade entre o cedente e o cessionário.

Diante do regramento exposto, que define a possibilidade de o sócio deixar de fazer parte de determinada sociedade, os sócios, que agiam em desconformidade com a finalidade da pessoa jurídica e, após a sua utilização inadequada, se retiram da sociedade, com o intuito de evitar possível constrição de seus bens, ficam solidariamente responsáveis pelas obrigações assumidas, pelo menos, durante o prazo de responsabilidade residual. ${ }^{62}$

58 NEGRÃO, Ricardo. Manual de direito comercial e de empresa: teoria da empresa e direito societário. 8 ed. São Paulo: Saraiva, 2011, p. 414.

59 Art. 1031. Nos casos em que a sociedade se resolver em relação a um sócio, o valor de sua quota, considerada pelo montante efetivamente realizado, liquidar-se-á, salvo disposição em contrário, com base na situação patrimonial da sociedade, à data da resolução, verificada em balanço especialmente levantado. §1ㅇ 0 capital social sofrerá a correspondente redução, salvo se os demais sócios suprirem o valor da quota. §2º A quota liquidada será paga em dinheiro no prazo de noventa dias, a partir da liquidação, salvo acordo, ou estipulação contratual em contrário.

60 Art. 1003. Parágrafo único. Até dois anos depois de averbada a modificação do contrato responde o cedente solidariamente com o cessionário, perante a sociedade e terceiros, pelas obrigações que tinha como sócio.

61 Art. 1.032. A retirada, exclusão ou morte do sócio, não o exime, ou a seus herdeiros, da responsabilidade pelas obrigações sociais anteriores, até dois anos após averbada a resolução da sociedade; nem nos dois primeiros casos, pelas posteriores e em igual prazo, enquanto não se requerer a averbação.

62 FORNACIARI JÚNIOR, Clito. Execução: Responsabilidade do Ex-sócio. Revista Magister de Direito Empresarial, Concorrencial e do Consumidor. Porto Alegre: Magister, Fev/Mar, 2005, p. 11. 
Não resta dúvida de que os sócios podem, por diferentes meios, sair da sociedade da qual fazem parte, bem como que a lei estabelece um período de responsabilidade residual pelas obrigações contraídas enquanto sócio. Mas, mesmo que passado o prazo de responsabilidade residual, não seria o caso de ex-sócio poder ser atingido por decisão que desconsidera a personalidade jurídica quando ficar evidenciado que, logo após o uso abusivo da personalidade jurídica, com nítido intento de frustrar os interesses dos credores, o sócio sai da sociedade, retirando-se ou cedendo suas participações societárias?

A jurisprudência tem sido favorável a possibilidade de aplicação da desconsideração para levantar o "véu" da pessoa jurídica, alcançando também o patrimônio do ex-sócio, que embora não faça mais parte da sociedade, participou da constituição da obrigação, a qual a pessoa jurídica não tem força para suportar porque serviu para a prática de estratégia abusiva em detrimento dos credores. ${ }^{63}$

Fato que deve ser levado em consideração para que seja deferida a desconsideração da personalidade jurídica é a data da constituição da dívida, ou seja, se ocorreu no período em que o sócio ainda fazia parte da sociedade. ${ }^{64}$ Nesse caso, será legítimo para figurar no polo passivo da demanda executiva o ex-sócio. Para demonstrar situação concreta neste sentido, o julgamento abaixo é ilustrativo:

Embargos à execução. Desconsideração da personalidade jurídica. Redirecionamento da execução na pessoa dos ex-sócios. 0 fato do afastamento do quadro social não impossibilita a desconsideração da personalidade jurídica, caracterizada a causa justificadora vinculando o ex sócio. A teoria da desconsideração da personalidade jurídica, em última análise, tem

63 BOEIRA, Alex Perozzo. Desconsideração da Personalidade Jurídica: Noções Gerais e Questões Controvertidas à Luz da Doutrina e da Jurisprudência. Disponível em: http://www.sintese.com/doutrina_integra.asp?id=1236. Acesso em 17 out. 2013.

64 TJRS, Agravo de Instrumento no 70022237507, 6a Câmara Cível, Rel. Des. Antônio Corrêa Palmeiro da Fontoura, julgado em 28.02.2008. 
como objetivo final a obtenção do crédito, e, nesse sentido, não é possível, diante dos elementos dos autos, emissão de cheques sem fundos, tipificado como crime, configurador de fraude, desconhecer a responsabilidade do ex-sócio da empresa que, na qualidade de representante legal, emitiu os títulos. A má-gestão da sociedade empresária já se iniciou ao tempo em que os apelantes figuravam como sócios da executada, emitindo inúmeros cheques sem fundos para pagamento de dívidas da empresa, a exemplo daqueles objetos da execução, e continuou ao tempo da nova composição do quadro social, pelos atuais sócios que, passando a integrar a sociedade, permaneceram não cumprindo com as obrigações sociais, culminando na desconsideração da personalidade jurídica. ${ }^{65}$

Nos julgados em que se afasta o atingimento do patrimônio de ex-sócio, utiliza-se o argumento de que não há que se falar nesta hipótese quando a saída do sócio se deu de forma regular, ou seja, com o devido registro na Junta Comercial da averbação de retirada deste da empresa, mas também porque não há evidências de fraude. Veja-se da ementa de julgado:

EMBARGOS DE TERCEIRO. PENHORA INCIDENTE SOBRE BENS DO DE CUJUS QUE REGULARMENTE RETIROU-SE DA SOCIEDADE. TEORIA DA DESCONSIDERAÇÃO DA PERSONALIDADE JURÍDICA. A teoria de desconsideração da personalidade jurídica da empresa tem aplicação restrita e somente se justifica sua aplicação, com o apanhar dos bens do sócio retirante, quando o procedimento de alteração do contrato social, com a retirada do sócio, não apresenta a necessária regularidade. Os bens do de cujus, cuja saída da sociedade foi normalmente registrada na Junta Comercial, não apresentando o procedimento qualquer indício de fraude, não respondem pelos débitos da empresa. ${ }^{66}$

Ora, nem precisaria ser dito que não havendo uso abusivo da personalidade jurídica, não há que se falar em desconsideração da personalidade jurídica nos casos em que o sócio sai da sociedade. Afinal, o principal requisito para aplicação do instituto é a

65 TJRS, Apelação Cível no 70057596900, 20a Câmara Cível, Rel. Des. Carlos Cini Marchionatti, julgado em 18.12.2013.

66 TJRS, Apelação nº 70009578527, 10aㅡ Câmara Cível, Rel. Des. Paulo Antônio Kretzmann, julgado em 21.10.2004. 
prática de algum fato grave que gere presunção de fraude contra os credores.

Além da saída regular do sócio, em alguns casos foi afastada a aplicação desconsideração da personalidade jurídica, levando em consideração o período transcorrido entre a retirada do sócio e a propositura da ação. Isso porque o artigo 1032 do Código Civil estabelece que com a retirada do sócio, este ficará solidariamente responsável pelas obrigações assumidas, somente pelo prazo de dois anos da averbação de retirada protocolizada no órgão responsável pelo registro. ${ }^{67}$

Entretanto, a utilização do limite temporal de dois anos é questão controversa na aplicação da desconsideração da personalidade jurídica para alcançar patrimônio de ex-sócio, já que a desconsideração não pode estar ligada a uma regra legal de responsabilidade. Precisa transcender isso quando o objetivo é punir aqueles que usam a pessoa jurídica para praticar atos abusivos que prejudicam os credores. 0 foco é o uso abusivo da personalidade, como se pode conferir do julgado abaixo:

\begin{abstract}
Embargos à execução. Desconsideração da personalidade jurídica em relação a ex-sócio. 0 fato do afastamento do quadro social não impossibilita a desconsideração da personalidade jurídica, caracterizada a causa justificadora vinculando o ex-sócio. São múltiplos os fatos e as circunstâncias que evidenciam o abuso da personalidade jurídica, com tamanha coerência e intensidade que o ex-sócio, por simulação e fraude, transformou-se em credor da sociedade empresária, prestando-lhe serviços de advocacia e sendo credor de honorários, com o dolo de prejudicar os demais credores. ${ }^{68}$
\end{abstract}

No caso em apreço, trata-se de recurso interposto por ex-sócio da pessoa jurídica que foi afetado pelo deferimento do pedido de desconsideração da personalidade jurídica. Enquanto 67 TJRS, Agravo de Instrumento no $70055174114,12^{\text {a }}$ Câmara Cível, Rel. Des. Umberto Guaspari Sudbrack, julgado em 15.08.2013.

68 TJRS, Apelação Cível no 70055846273, 20a Câmara Cível, Rel. Des. Carlos Cini Marchionatti, julgado em 11.12.2013. 
este fazia parte da sociedade, agiu de forma fraudulenta, assumindo inúmeras obrigações em montantes elevadíssimos, com os quais a empresa não tinha como arcar.

Não bastassem todas as fraudes cometidas, enquanto ainda era sócio, por ser advogado, assumiu a defesa da empresa nos processos que ela estava sofrendo, firmando contrato de honorários de elevados valores, ou seja, contratou a si mesmo para a prestação de serviços advocatícios, já que era procurador da empresa, na época, para a prática de todos os atos, inclusive de administração. Depois de ter se autocontratado, o sócio-advogado saiu da sociedade, através da cessão das suas quotas, com intuito de garantir que seu patrimônio particular não fosse afetado pelas execuções em andamento, bem como retirando valores consideráveis da empresa através da cobrança de honorários.

No referido processo foi deferida, em primeiro grau, a desconsideração da personalidade jurídica para alcançar o patrimônio do ex-sócio, que se utilizou da personalidade jurídica como instrumento para o cometimento de tais atos, mesmo já transcorrido período superior a dois anos da saída do sócio, sendo integralmente mantida a sentença em grau recursal, pelos fundamentos expostos no julgamento do juízo a quo.

Nesse sentido, o prazo de dois anos da responsabilidade residual de sócio que sai da sociedade não deve limitar o prazo para propositura da ação na qual se discuta a responsabilidade de sócio que agiu contra a finalidade da pessoa jurídica. Assim entende Rubens Requião:

Por outro lado, o art. 1.032 não estabelece prazo de prescrição para os efeitos das situações jurídicas previstas no contrato social ou derivadas de outros atos dos sócios, enquanto sócios. Os efeitos jurídicos dos atos praticados pelo sócio, durante o período em que foi sócio ou participou da gestão da sociedade, não se extinguirão ao final de dois anos a contar do afastamento do sócio do quadro social. Nesse sentido, havendo obrigação societária pela qual o sócio tenha responsabilidade pessoal, ou mesmo solidária ou subsidiária, criada ou tornada concreta ao tempo em 
que era sócio, ou tornada líquida e certa no período de dois anos após o afastamento deste, mesmo que ocorra este afastamento e decorra o prazo de dois anos, continuará o sócio sujeito àquela responsabilidade. Esta perdurará até a sua extinção, por pagamento, prescrição etc. ${ }^{69}$

Para demonstrar caso concreto em que o ex-sócio foi atingido pela decisão de desconsideração da personalidade jurídica é interessante a análise do julgamento do agravo de instrumento assim ementado:

AGRAVO DE INSTRUMENTO. CUMPRIMENTO DE SENTENÇA. DESCONSIDERAÇÃO DA PERSONALIDADE JURÍDICA. Presentes os pressupostos do art. 50 do Código Civil, pelo uso abusivo da personificação societária para prejudicar terceiros, deve ser desconsiderada a personalidade jurídica, com o redirecionamento do feito contra o ex-sócio da empresa, seu diretor presidente à época da constituição da dívida. Agravo provido. ${ }^{70}$

0 agravo de instrumento foi proposto para buscar a aplicação da desconsideração da personalidade jurídica de forma extensiva ao ex-sócio que ainda participava da sociedade quando da constituição da dívida, bem como de momento posterior em que se evidenciou a fraude contra os credores praticada a partir de um esvaziamento preordenado do patrimônio empresarial.

Tratava-se de ação de cobrança de valores de dois cheques, a qual foi julgada procedente. Já no início da fase de cumprimento de sentença, após inúmeras diligências com intuito de localizar bens da empresa devedora que pudessem saldar a dívida, evidenciou-se o fato de que esta não possuía bens, sendo apenas uma empresa "de fachada".

No caso, a fraude ficou comprovada porque a data da saída do até então sócio majoritário e administrador da empresa se deu ato contínuo ao esvaziamento patrimonial da sociedade. No

69 REQUIÃO, Rubens. Curso de Direito Comercial. 30. ed. rev. e atual. São Paulo: Saraiva, 2011. V.1, p. 453.

70 TJRS, Agravo de Instrumento no 70052447752, 11a Câmara Cível, Rel. Des. Bayard Ney de Freitas Barcelos, julgado em 25.09.2013. 
ano anterior à saída do sócio, o balanço patrimonial referente ao estoque de bens apresentava 15 milhões de reais, o que foi demonstrado através da ata da Assembleia Geral Ordinária, publicada em jornal de grande circulação.

Diante de todos os fatos narrados e devidamente comprovados no recurso de agravo de instrumento interposto pela empresa credora, o Desembargador Relator Bayard Ney de Freitas Barcelos, votou pelo provimento do recurso, entendendo que o caso do referido processo enquadrava-se nas hipóteses de aplicação da Disregard Doctrine. Os demais desembargadores, que participaram do julgamento, acompanharam o voto do relator.

Trata-se, pois de uso adequado do instituto. Isso porque se verificou um fato grave que gerou presunção de fraude e uso abusivo da pessoa jurídica, atingindo-se o patrimônio daquele que foi responsável por tal ato, ainda que no momento da decisão judicial, não fizesse mais parte da sociedade em questão. Aliás, ressalta-se que tal posicionamento vincula-se a aplicação da desconsideração pela concepção objetivista da teoria maior, se é que assim ainda se pode chamar. A diferença está no simples fato de poder atingir o patrimônio de quem já não é mais sócio da sociedade. De forma alguma, tal possibilidade deve ser interpretada na linha de raciocínio de que a simples insolvência da pessoa jurídica autoriza a desconsideração da personalidade.

Por fim, no que toca à possibilidade de ação de regresso do ex-sócio afetado pelos efeitos da desconsideração da personalidade jurídica, contra a sociedade e os sócios que atualmente a compõem, manifestou-se o Tribunal de Justiça do Rio Grande do Sul, entendendo não ser cabível:

Apelação cível. Ação condenatória. Ex-sócio que foi responsabilizado na Justiça do Trabalho por dívida trabalhista reconhecida em período no qual ainda era sócio da empresa. Caso concreto. Matéria de fato. Análise das provas. Situação decidida no âmbito da Justiça do Trabalho, onde houve desconsideração da pessoa jurídica e responsabilização do ex-sócio, 
tudo na forma do art. 1.003 do Código Civil. Não cabimento de direito de regresso contra a empresa ou contra os novos sócios, cessionários, pelos termos da recíproca quitação operada na alteração do contrato social. Apelo não provido. ${ }^{71}$

Como visto, quando o sócio deixa de fazer parte de sociedade, seja por cessão de quotas ou ações ou pelo exercício do direito de retirada, mesmo gozando de limitação da sua responsabilidade, para evitar o uso inadequado da personalidade jurídica, tem-se admitido a desconsideração da personalidade jurídica para alcançar o patrimônio do ex-sócio, posição que vai ao encontro do objetivo do instituto. A autonomia patrimonial da pessoa jurídica é princípio que merece todo o respeito, mas não deve prevalecer quando os integrantes da pessoa jurídica utilizam-se desta garantia para burlar o cumprimento de obrigações assumidas.

\section{CONSIDERAÇÕES FINAIS}

Inequívoca é a importância do instituto da desconsideração da personalidade jurídica já que é a ferramenta utilizada para compelir o uso inadequado da pessoa jurídica, mas preservando esta na medida em que seus efeitos são episódicos e não implicam em dissolução da sociedade. Claro que para fins de aplicação do instituto da desconsideração, necessária é a evidência de fatos graves que geram a presunção da fraude ou uso abusivo da personalidade jurídica em detrimento dos credores. Do contrário, estar-se-ia ampliando demasiadamente o instituto da desconsideração o que agrava a crise pela qual passa a própria pessoa jurídica, o princípio da autonomia patrimonial da pessoa jurídica e a regra da limitação da responsabilidade dos sócios.

0 interessante desse estudo é a demonstração de que o instituo da desconsideração pode ser utilizado não somente para alcançar o patrimônio do sócio que utilizou de forma abusiva da

71 TJRS, Apelação Cível no 70057741159, 6a Câmara Cível, Rel. Des. Ney Wiedemann Neto, julgado em 20.03.2014. 
personalidade jurídica, o que é amplamente aceito, mas também, daquele que após o cometimento do referido ato, se retirou da sociedade, na expectativa de burlar o cumprimento da obrigação assumida e evitar constrição de seus bens particulares para satisfação da obrigação social. E mais, não sendo assegurado ao ex-sócio atingido pela desconsideração, o exercício do direito de regresso contra a sociedade e sócios atuais.

Tal aplicação justifica-se pelo fato de que a desconsideração da personalidade jurídica almeja a coibição do cometimento de ato fraudulento; pune o uso abusivo da personalidade jurídica.

No atual cenário brasileiro, vive-se um momento de grande descrença no Poder Judiciário, haja vista a morosidade do processo que, além disso, muitas vezes, não consegue assegurar a efetiva satisfação do direito declarado. Nesse contexto, evidencia-se a importância da desconsideração da personalidade jurídica que abrevia o tempo que se levaria buscando a anulação de um negócio jurídico fraudulento, para posteriormente buscar o seu ressarcimento.

Ademais, considerando a finalidade da desconsideração da personalidade jurídica, a sua aplicação de forma estendida, ou seja, em relação às hipóteses especiais, como é o caso da desconsideração para o atingimento do patrimônio de ex-sócio, mostrase como instrumento para garantir a efetividade da justiça.

\section{REFERÊNCIAS}

BOEIRA, Alex Perozzo. Desconsideração da Personalidade Jurídica: Noções Gerais e Questões Controvertidas à Luz da Doutrina e da Jurisprudência. Disponível em: http://www.sintese.com/doutrina_integra.asp?id=1236. Acesso em 17 out. 2013.

BLOK, Marcela. Desconsideração da personalidade jurídica; uma visão contemporânea. Revista de Direito Bancário e do Mercado de Capitais. São Paulo: Revista dos Tribunais, Ano 16, vol. 59, jan/mar. 2013.

CANTALI, Fernanda Borghetti; GUENO, Aline Wolz. Anotações aos artigo 133 a 137. In: MELLO, Rafael Corte; GIORGI JÚNIOR, Rômulo Ponticelli. 
(Orgs.) Novo Código de Processo Civil Anotado. Charleston, EUA: CreateSpace Independent Publishing Platform, 2015.

COELHO, Fábio Ulhoa. Desconsideração da personalidade jurídica. São Paulo: Editora Revista dos Tribunais, 1983.

2013. V.1.

Curso de direito comercial. 10.ed. rev. e atual. São Paulo: Saraiva, . Curso de direito comercial.10.ed. rev. e atual. São Paulo: Saraiva, 2007. V.2.

. Manual de Direito Comercial. 28.ed. rev. atual. e ampl. São Paulo: Editora Revista dos Tribunais, 2016.

FORNACIARI JÚNIOR, Clito. Execução: Responsabilidade do Ex-sócio. Revista Magister de Direito Empresarial, Concorrencial e do Consumidor. Porto Alegre: Magister, Fev/Mar, 2005.

GAMA, Guilherme Calmon Nogueira da. Desconsideração da personalidade jurídica: visão da jurisprudência. São Paulo: Atlas, 2009.

MADALENO, Rolf. A desconsideração judicial da pessoa jurídica e da interposta pessoa física no direito de família e no direito das sucessões. 2.ed. Rio de Janeiro: Forense, 2009.

MARINONI, Luiz Guilherme; MITIDIERO, Daniel. O projeto do CPC: críticas e propostas. São Paulo: RT, 2010.

NEGRÃO, Ricardo. Manual de direito comercial e de empresa: teoria da empresa e direito societário. 8.ed. São Paulo: Saraiva, 2011.

PEREZ, Viviane. Função social da empresa, uma proposta de sistematização do conceito. In: ALVES, Alexandre Fereira de Assunção; GAMA, Guilherme Calmon Nogueira da. (Coords.) Temas de Direito Civil Empresarial. Rio de Janeiro: Renovar, 2008.

RAMOS, André Luiz Santa Cruz. Direito Empresarial Esquematizado. 6.ed. rev., atual. e ampl. Rio de Janeiro: Forense; São Paulo: Método, 2016.

Direito Empresarial Esquematizado. 3.ed. rev., atual. e ampl. Rio de Janeiro: Forense; São Paulo: Método, 2013.

REQUIÃO, Rubens. Curso de Direito Comercial. 30.ed. rev. e atual. São Paulo: Saraiva, 2011. V.1.

SILVA, Alexandre Couto. A aplicação da desconsideração da personalidade jurídica no direito brasileiro. 2.ed. Rio de Janeiro: Forense, 2009. 
SOUZA, André Pagani de. Desconsideração da personalidade jurídica: aspectos processuais. 2.ed. São Paulo: Saraiva, 2011.

VON ADAMEK, Marcelo Vieira; FRANÇA, Erasmo Valladão Azevedo e Novaes. Empresa Individual de Responsabilidade Limitada (Lei $\mathrm{n}^{\circ}$ 12.441/2011): Anotações. In: Revista de Direito Mercantil - RDM. São Paulo: Malheiros, 2011.

. Notas sobre a sociedade perpétua. Artigo gentilmente cedido pelos autores. 